\title{
Management of Pine Forests for Selected Wildlife in Florida'
}

\author{
Wayne R. Marion, George W. Tanner, Holly K. Ober, and Matthew Werner²
}

Pine forests are common in the southeastern Coastal Plain and extensive in Florida. Many of these forests are managed for timber production. As the total number of forested acres in Florida diminishes, the demand for forest products continues to increase. Other resource needs must be satisfied as well--habitat for wildlife species directly dependent upon forests is an excellent example. The need for forest products such as timber and the provisioning of habitat for wildlife are frequently seen as being in competition. This is because forest management activities that enhance timber production are not necessarily good for all wildlife, and activities that enhance wildlife are not necessarily best for timber production. However, it is possible for a forest to sustain both wildlife and successful forest products industries. Most forest management practices will have an effect on wildlife habitat and therefore result in changes in some part of the wildlife community, but with careful management, habitat used for timber production can sustain healthy wildlife populations.

Pine flatwoods (Figure 1) are the forest type that is typically most intensively managed for commercial purposes in Florida, and for this reason, management options favoring wildlife in pine flatwoods will be emphasized in this publication. We will attempt to illustrate ways in which timber and wildlife management can be successfully

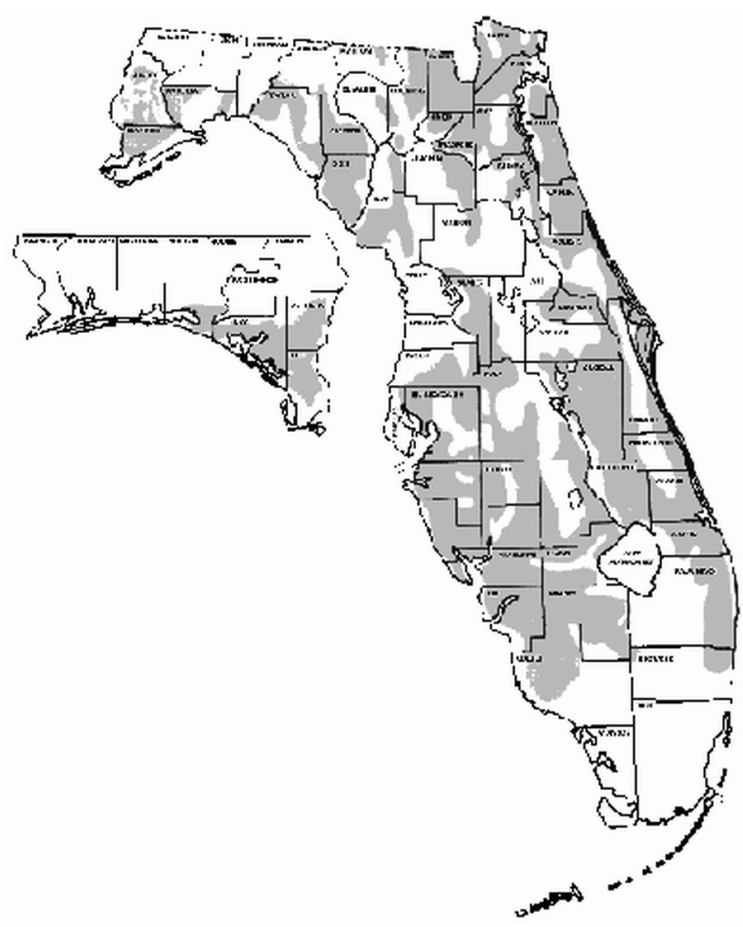

Figure 1. Pine flatwood forests are common throughout Florida.

combined using an integrated approach to fulfill multiple resource objectives.

1. This document is CIR706, one of a series of the Wildlife Ecology and Conservation Department, Florida Cooperative Extension Service, Institute of Food and Agricultural Sciences, University of Florida. Original publication date October, 1986. Revised August 2011. Reviewed August 2011. Visit the EDIS Web Site at http://edis.ifas.ufl.edu.

2. Wayne R. Marion, George W. Tanner, and Holly K. Ober are, respectively, a former associate professor, emeritus professor, and assistant professor and extension specialist in the Department of Wildlife Ecology and Conservation, Cooperative Extension Service, Institute of Food and Agricultural Sciences, University of Florida, Gainesville FL 32611. Matthew Werner is a former graduate research assistant, State University of New York, College of Environmental Science and Forestry, Syracuse, NY 13210. 


\section{What Are Pine Flatwoods?}

Flatwoods are typically found on poorly drained, sandy soils intermediate in moisture content between wetter bottomlands and drier uplands. Overstory of these woodlands consists mainly of longleaf, slash, and loblolly pines, although pond pine and shortleaf pine do occur in localized areas. Intermixed with the flatwoods are small bayheads, cypress domes, prairies, marshes, and hardwood swamps.

Fire originally played a major role in determining the overstory composition of flatwoods, since longleaf pines are relatively fire-tolerant and slash pines are not. Purposeful fire suppression has greatly altered the balance of ecological forces and caused obvious changes in natural vegetative communities. So, too, has the switch from natural, lightning-caused fires (which traditionally occurred during the summer) to prescribed fire during the dormant season (late winter to early spring). Conversion of natural longleaf, slash pine, and hardwood forests to slash and loblolly plantations throughout the southeastern Coastal Plain has further altered natural vegetative patterns.

The shrub layer of flatwoods forests often includes blackberry, dwarf huckleberry, fetterbush, gallberry, saw palmetto, and wax myrtle. These evergreens produce fruits and berries that are important wildlife foods. Grasses on the flatwoods forest floor often include broom-sedge, chalky bluestem, Indian grass, panicum, paspalum, and wiregrass. Associated herbs can include beggarweed, deer tongue, grassleaf gold aster, partridge pea, and rabbit tobacco. A variety of wildlife species and sometimes domestic livestock graze in Florida flatwoods.

\section{Flatwoods Wildlife}

The term wildlife includes all of the free-ranging, wild vertebrate species inhabiting an area. In the Southeast, there are about 400 resident species of mammals, birds, amphibians, and reptiles. Of course, no one parcel of land can support all 400 species. In fact, each species, and sometimes each life stage of a species, requires a unique set of habitat conditions. Consequently, different management techniques favor different wildlife species. Not all wildlife species in an area will react in the same way to a particular management practice. There are a wide range of responses to each practice, depending on the species being considered. In general, the larger a parcel of land and the greater the variety of habitat types present, the greater the variety of wildlife species that can be supported there.

There are many reasons for managing wildlife. One reason is to provide habitat for rare species. Preservation of endangered species, such as the red-cockaded woodpecker, requires careful management of specific habitat types to provide features suited to those species. Another reason to manage wildlife is for recreational activities, such as hunting and wildlife observation. Throughout the Southeast, approximately 10 percent of resident birds and 20 percent of resident mammals are considered game species suitable for hunting. Leasing of hunting rights on private forestlands is becoming a more typical means of gaining access to game. Hunting leases can provide substantial annual income for the owner of well-managed forests.

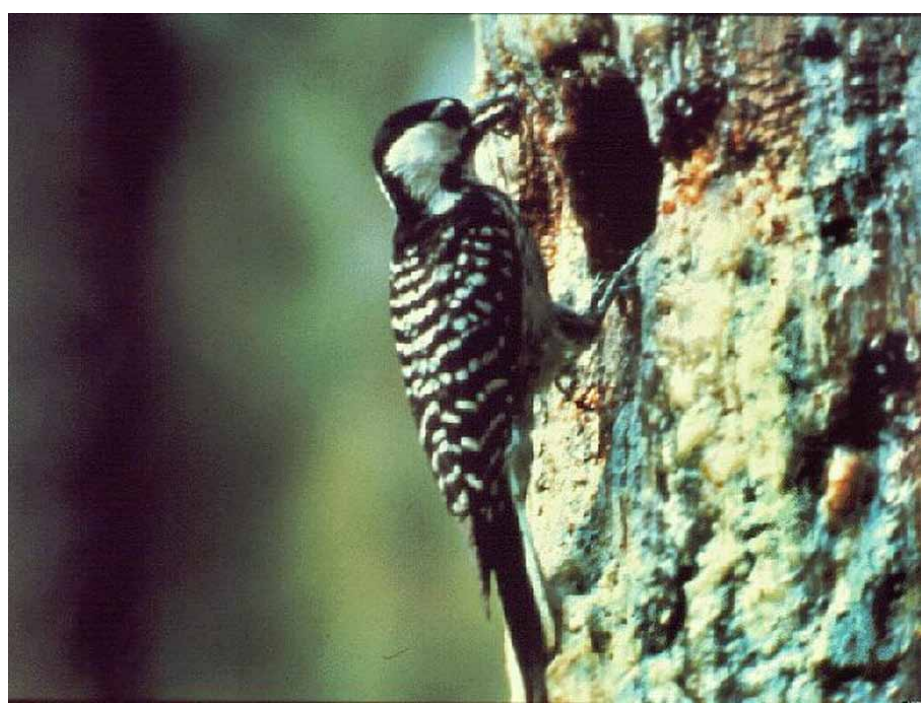

Figure 2. Red-cockaded woodpeckers are endangered.

Nationally, only about 20 percent of wildlife-related recreational activity involves hunting. Americans involved in wildlife observation (e.g., bird watching) outnumber Americans involved in hunting by more than two to one. In addition to resident wildlife species, the forests of the southeastern United States support a massive influx of migratory bird species between the fall and spring each year. These are but a few of the worthwhile reasons to manage forests to favor wildlife.

\section{Changing Forest Structure for Wildlife}

The ability to produce timber and pulpwood in southern pine forests is continually improving. Examples of new techniques include genetic stock improvement, planting of superior seedlings, and use of various herbicides and insecticides. These developments help foresters meet growing demands for pulp and timber. But how do these developments affect wildlife? 


\section{Diversity}

Diversity is a technical term used to describe variety. The techniques and developments listed above tend to reduce vegetative diversity in flatwoods. As the structural diversity (differences in vegetation in terms of height and spatial arrangement of the plants) of forests is reduced, so is their capability to support various and abundant wildlife species. Forest structural diversity is considered to be the main determinant of the number and abundance of wildlife species. Every species has a unique set of habitat requirements (food, cover, water, and space). Maintenance or enhancement of structural diversity, both within and among forest stands, maintains or increases the types of habitats available for wildlife.

\section{Within-Stand Diversity}

Establishment of even-aged plantations, while facilitating timber production and harvest, has greatly reduced withinstand structural diversity. Low- and mid-story vegetation are often poorly developed in such stands, especially after closure of the pine canopy. Because each tree species has a unique growth form, forest stands with many species have high structural diversity; in contrast, stands with only one or two species have low structural diversity.

Temporal diversity is created when many different species of plants are available to provide wildlife with year-round sources of food and cover. A variety of sources of food or cover also assures that if one species fails, another will likely thrive. Additional information on providing food for forest wildlife is available at http://edis.ifas.ufl.edu/pdffiles/FR/ FR06200.pdf.

Snags and cavity trees are another component of forest structural diversity important as wildlife habitat. A snag is a standing dead or dying tree that provides perching and nesting sites for many different animals. Snags also are rich in the insects many wildlife species eat. It is useful to leave a few snags standing both in the forest and in more open areas. Additional information on the importance of snags and cavity trees is available at http://edis.ifas.ufl.edu/ pdffiles/UW/UW27700.pdf.

\section{Among-Stand Diversity}

Usually, managing a multiple-use forest to increase among-stand diversity is the most efficient way to enhance wildlife populations. Even-aged stands of trees tend to have low within-stand diversity, but select wildlife can thrive on a plantation if horizontal, or landscape, diversity is maintained through the intermingling of stands of different ages and types.
Landscape characteristics such as topography, soil type, and related physical and biological features should dictate the design of multiple-use forests. The boundaries of a management block should be defined on an ecological basis, such as watersheds and drainages, rather than on historical boundaries. Additionally, the site should dictate which tree species are managed. For instance, hardwood trees should be left or planted in areas normally not suitable or productive for pines, such as swamps, bottomlands, and pond edges. Hardwood forests normally produce and support two or more times the wildlife populations of coniferous forests. They are a highly desirable feature of among-stand forest structural diversity.

Consider the life-cycle requirements of larger wildlife species when planning the locations of habitat units. Units large enough to provide for breeding territories and home ranges of the species you want to foster will be most useful. Also, because it is common for wildlife species to use different habitats at different times of day or during different seasons, it is essential to provide habitat corridors and travel lanes to allow animals to move between habitat units and across open areas. These habitat corridors will also encourage animals to recolonize isolated patches.

\section{Edge}

An important concept in ecology worthy of consideration when managing wildlife is that of edge. Edge occurs in the zone where two different habitats meet-sometimes called the ecotone. Both habitats contribute plant and animal species to the edge, and the combination of both in close proximity makes the edge more valuable to wildlife than either habitat alone.

Create good-quality edge habitat by placing two dramatically different habitats side by side for an extended period--at least several years. For example, a clearcut area next to a mature stand might create quality edge for only one year if the following year the adjacent stand is also cut. A higher quality edge will occur if a clearcut area is placed next to a mid-rotation stand. Long or irregularly shaped clearcut areas ( $\mathrm{C}$ and $\mathrm{D}$ in Figure 3) will create more edge than square or circular clearcut areas (A and B in Figure 3 ). If the edges of the cut follow irregular contours, the benefits of the edge will be even greater. Finally, coverts are formed when three or more habitat types meet at one point. Coverts provide additional advantages to edge zones for some wildlife species because they provide an even greater array of resources in close proximity. 


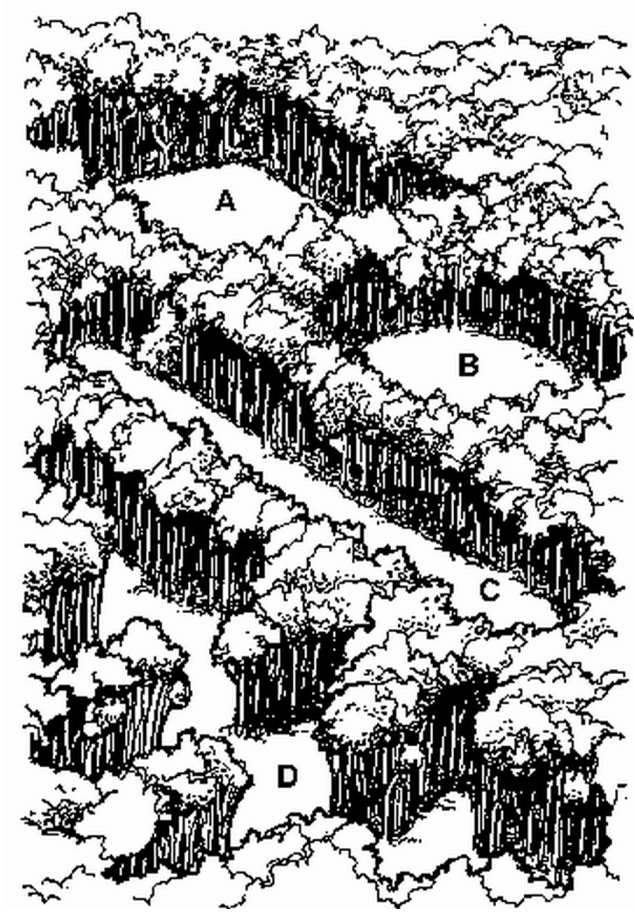

Figure 3. Varying amounts of edge are created by clearcuts of different sizes and shapes.

Access roads, powerlines, and firelanes also are habitat features that can be managed to greatly enhance landscape diversity. High-nutrient forage plants can be seeded in these areas to provide quality food for wildlife. Mowing of existing weedy vegetation along roadsides can renew forages for many wildlife species. Irregular roads provide greater quantities of valuable forage than straight roads because they provide more edge zone. Open areas like these also are excellent insect habitats. Limiting access of people to these areas will encourage their use by wildlife.

In summary, a mixture of relatively small, even-aged pine stands at various stages of growth, intermingled with each other and with natural communities (streams, hardwoods, cypress domes, etc.) will provide edge and increase amongstand forest structural diversity.

\section{Developing a Management Plan}

The forest is constantly changing. Many changes are subtle and gradual, such as the replacement of plant and animal species by other species. You may not notice these changes, but they are always occurring in a process known as ecological succession.

Forest management intended to benefit wildlife often involves changing the natural course of plant succession to produce habitat conditions that meet the needs of the wildlife species desired. In essence, management practices allow you to somewhat control which native wildlife species will be present on a forestland. A carefully thought-out management plan helps to do this most effectively. For more information on forest management plans, see http:// edis.ifas.ufl.edu/pdffiles/FR/FR12600.pdf.

A management plan requires several essential steps. First, identify your needs and interests, and your short- and long-term objectives. How often do you want to harvest trees? What types of wildlife do you want to encourage? How intensive will your management input be?

Next, inventory the habitats on your land so that you know what you have to work with. Create management blocks based on the habitat types you identify.

Third, learn about the habitat requirements of desired wildlife species. This step may require further reading, or contacting the Cooperative Extension Service or the Florida Fish and Wildlife Conservation Commission. Be sensitive to wildlife needs for cover, food, and water, and arrange these resources effectively to provide ready access to animals. Many animals depend on insects as food sources, so choose insecticides carefully and apply them judiciously so as not to suppress insect populations in areas not devoted to production. Whenever possible, protect animals' natural sources of water by keeping streams well vegetated and by using procedures to prevent soil erosion during harvesting and other operations.

When you have determined your objectives, choose among the following silvicultural (forest management) practices to achieve them.

\section{Silvicultural Practices and Their Effects on Wildlife}

In general, intensified forest management reduces within-stand structural diversity and results in the loss of several habitat characteristics of importance to wildlife. Among-stand diversity can provide partial compensation for the loss of within-stand diversity, however, and will allow for the development of habitat conditions suitable for a wide array of wildlife. Understanding common timber management practices and their effects on forest structural diversity and wildlife will assist in the management of forestlands for wildlife (see Table 1).

\section{Site Conversion}

The conversion of natural forests to slash or loblolly pine plantations has drastic effects on wildlife populations. 
Site conversion typically results in the loss of both the naturally diverse characteristics of the original forest type and the among-stand features created by the intermixing of different forest types. Natural longleaf pine forests in the southeastern Coastal Plain seem to be superior as wildlife habitats because they support a greater variety of herbaceous species and insects, making them more attractive to both plant- and insect-eating wildlife.

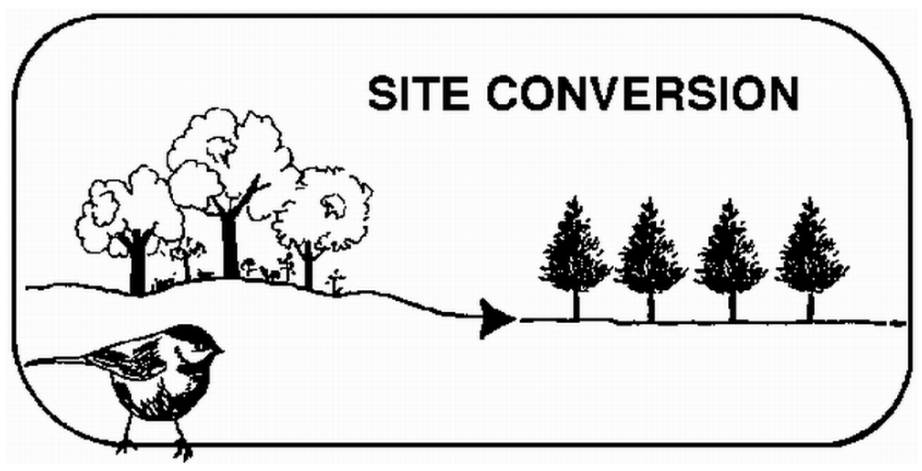

Figure 4. Site conversion changes the dominant species of trees in a forest stand.

By leaving most tree species and natural plant communities intact, you can usually retain valuable diversity over broad areas. The more a stand has been changed from its natural condition, the more management efforts will be required to put it back into its previous condition. Wet areas not suitable for pine growth--such as cypress domes, bayheads, swamps, and marshes--provide important wildlife habitats and refuges. Draining wetlands and converting them to conditions suitable for pine growth is detrimental to native wildlife and should be avoided if your objective is to promote wildlife.

To understand the long-term effects of site conversion, consider pine plantations that have been planted on "old-field" sites. Old-field sites are locations converted to fields for agricultural cultivation. In general, old-field sites yield greater pine growth and less understory growth than previously non-cultivated sites. The lack of understory vegetation typical of old-field plantations results from the lack of seeds in the soil. Studies show that there is a steady decrease in understory deer browse as old-field plantations grow older. In contrast, the peak browse value of plantations on previously forested sites occurs in 5- to 10-year-old stands. The lack of structural diversity of vegetative layers in old-field plantations makes them less attractive to wildlife than plantations on previously forested sites. Consider carefully before embarking upon a site conversion that could destroy natural attributes such as the seed legacy in the soil and permanently alter the habitat to the detriment of the wildlife you hope to encourage.

\section{Clearcutting}

Clearcutting is the harvesting of all commercially valuable trees in an area. In the southeastern Coastal Plain, clearcutting is the most common timber harvest technique. No other management practice has more immediate and dramatic effects on animals and their habitats. For example, clearcutting typically excludes from a site all birds and mammals that feed and nest in tree crowns. The degree of impact depends on the age of the trees, the plant species present, stocking density, and the size and shape of the stands removed. In northern Florida, approximately 40 percent of breeding forest bird species are cavity-nesters, and clearcutting has drastic effects on local populations of these birds. Competition among animals for nesting cavities is intense; thus, clearcut, short-rotational management systems may limit abundance of these species. Leave snags and trees with cavities standing whenever possible to fulfill the requirements of cavity-dwelling species of wildlife.

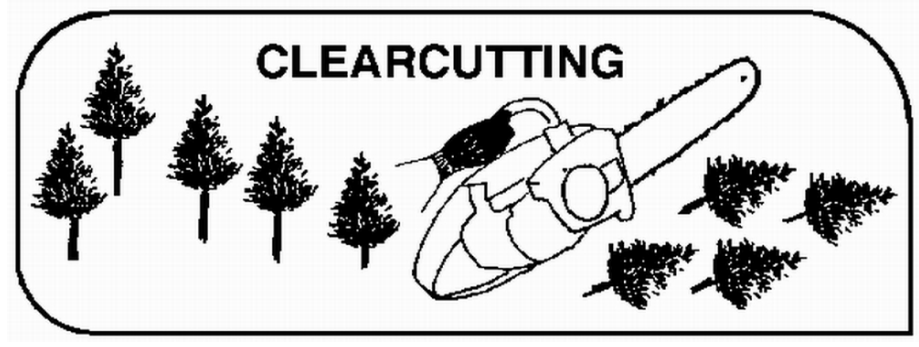

Figure 5. Clearcutting is the most common timber harvest technique in the southeastern Coastal Plain.

Clearcutting is favorable for some species and unfavorable for others. Removal of the shading effects of the forest overstory allows an increased growth of understory vegetation, which may significantly benefit ground-level feeders, such as white-tailed deer, northern bobwhite quail, eastern meadowlarks, cottontails, and wild turkeys. These species require open conditions and early successional plant communities. Production of ground-level fruits available for consumption by wildlife is greatest during the first few years following clearcutting. Studies of Florida flatwoods demonstrate that clearcuts and edges of clearcuts are also important habitats for wintering bird species.

The size and shape of a clearcut site determine the degree of impact on wildlife. Most animals with small home ranges will not use large square or circular cuts of more than 250 
acres, and few species will use the centers of large clearings. Large animals, such as deer, use only the outermost 100 yards of large clearcuts, where forest cover is nearby. Smaller, elongated clearcut areas of less than 100 acres are more favorable for most species, since they allow greater use of the food sources within clearings and create more edges. Long, narrow clearcut areas can include territories and home ranges of more animals, allowing more individuals to benefit from the close proximity of food and cover (see Figure 3).

Several alternative regeneration methods may be used instead of clearcutting followed by replanting with seedlings. The two-cut regeneration system, or shelterwood, is an inexpensive, natural way to establish young pines before harvesting all mature trees. Make the first cut a few years before the final harvest, and use prescribed burns to prepare the site for seedling establishment. Thin the stand heavily, leaving only the best-formed trees to provide seed for regeneration. Harvest the remaining trees after a uniform growth of young pines has appeared. The seed tree regeneration system is similar to the shelterwood system, except that it leaves fewer trees standing. The main disadvantage is that the small volume of timber left may be difficult to sell. Both of these systems are valuable in that they generally increase habitat and wildlife diversity. They produce abundant ground level forage and frequently support substantial bird populations. However, germination, spacing, and survival of seedlings are unpredictable.

Clearcutting usually is followed by a number of treatments that prepare the site for the planting of tree seedlings. These treatments may include any combination of the following: burning or chopping of debris and piling it in windrows with a K-G blade, stump removal, herbicide use, harrowing, bedding, and ditching. The combination and intensity of these site preparation techniques determine their impact on wildlife. Very intensive site preparation practically eliminates the existing plant communities from the site, and establishment of desirable wildlife foods and cover is consequently delayed.

\section{Site Preparation}

The length of time required for growing pines to dominate a site also depends on the intensity of site preparation. This is an extremely important point in determining the species of wildlife that will be supported. When the pines are young and the sparse crowns allow sunlight through, wildlife species that prefer open conditions (early successional habitats) will use the site. These include northern bobwhite quail, cottontail rabbits, cotton rats, and sparrows. Young forests also supply abundant food for deer and turkeys. These habitats and animals decline as the pine stand approaches crown closure. After closure and before thinning or burning occurs, a pine plantation provides few food plants and little more than escape and nesting cover for many wildlife species.

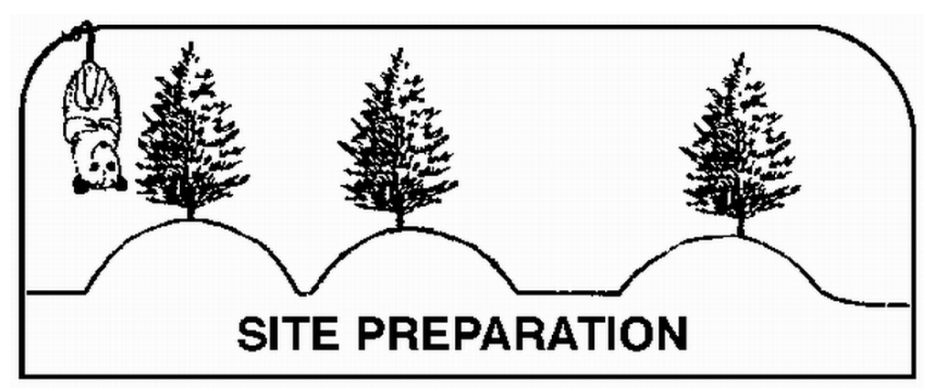

Figure 6. Site preparation activities influence which wildlife species a stand will support.

In general, high-intensity site preparation hastens development of the canopy, and in so doing diminishes wildlife habitat. A study comparing high-intensity with low-intensity site preparation demonstrated that, after nine years, low-intensity sites had a well-developed grass/ saw palmetto understory and little growth of other woody shrubs. The understory supported a large number of insects, which in turn sustained a variety of insect-feeding animals, including opossums, armadillos, and shrews. In comparison, high-intensity site preparation had a greater degree of crown closure and a more developed shrub layer. This greatly reduced the amount of ground forage.

Although site preparation techniques such as cultivation and fertilization may reduce the total understory, researchers have found that the proportion of desirable understory forage plants is sometimes greatly increased. After 12 years, prepared sites provided better deer habitat than nonprepared sites. The researchers concluded that intensive pine culture can be compatible with maintaining deer habitat. Other site preparation techniques can help wildlife also. Burning in Florida flatwoods is often beneficial. Also, the piling of debris to form windrows provides cover for deer, bobwhites, and cottontails, but may have long-lasting negative impacts on native groundcover vegetation that serves as food for these species. In general, when considering a variety of wildlife species, less intensive levels of site preparation are more favorable than more intensive levels. However, certain game species, particularly white-tailed deer, are helped in some cases by higher intensity site preparation.

Controlled use of fire in Florida flatwoods is a valuable management tool. Pine forestlands can be burned to 
accomplish the following goals: 1 ) to dispose of debris from timber harvesting operations and to prepare the site for planting, 2) to reduce understory and litter to prevent catastrophic wildfires, 3) to control insect pests and diseases, 4) to increase the quantity and quality of edible plants for cattle and/or wildlife, 5) to recycle nutrients bound up in plant litter and debris back into the soil, and 6) to alter or improve the structural aspects of wildlife habitats.

Native plants and animals of Florida flatwoods have evolved in the presence of frequent burning in many pine forest types. Shrubs such as saw palmetto, pawpaw, yaupon, sweetleaf, sumac, and blackberry all respond vigorously to periodic burning. Other species are limited by fire. Exclusion of fire for the first 10 or 15 years in pine plantations may, therefore, have drastic effects on the development of the forest understory, which in turn affects the suitability of these areas for wildlife.

\section{Prescribed Burning}

Burning schedules are extremely important to the development of habitat conditions favorable for various wildlife species. A one- to two-year burning schedule keeps the understory open and creates habitat favorable for northern bobwhite quail. A three- to five-year burning schedule allows for development of browse and cover plants, thereby favoring deer and turkeys. A three- to five-year schedule also allows the accumulation of sufficient fuel to support the next prescribed burn, and is most compatible with timber production in pine flatwoods.

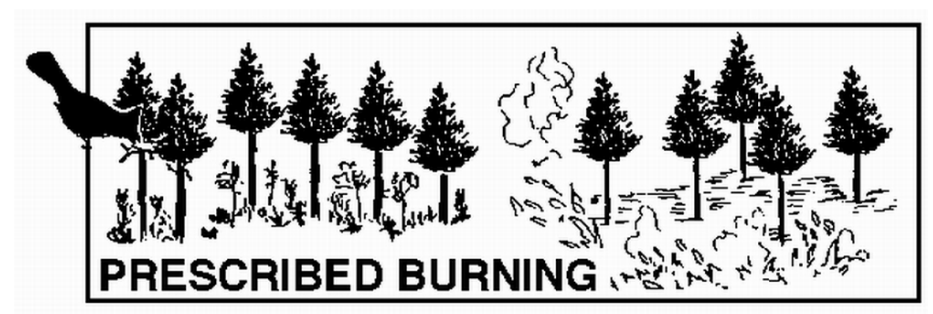

Figure 7. Prescribed burning in pine flatwoods improves habitat for many species of wildlife.

When planning a prescribed burn, seek the advice of a professional forester or technician. A planned burn carried out in a careful and knowledgeable manner can be a safe and effective management tool. Burns are often conducted in the winter shortly after a rain, although there is some evidence that summer burns were historically more common and may be better for wildlife because of their "patchy" nature. A day with a slow, steady wind is desirable.
Keeping the blocks of land to be burned relatively small will allow you to stop the burn any time conditions become dangerous. The areas to be burned should be surrounded by natural barriers or plowed fire breaks.

Set your prescribed fire on the downwind side of the site so that the fire will burn slowly back into the wind. Such a fire is considered safe, provided the wind does not change direction. The upper surface layer of pine needles and grass will fuel the fire, but the lower organic layer should be moist enough to resist burning. A slow, steady wind will help to spread the heat before it rises into the tree crowns, and will facilitate a backfire. After burning, always make follow-up observations to prevent flare-ups from smoldering stumps or logs.

\section{Forest Fertilization}

Florida pine flatwoods are often lacking in certain nutrients, especially phosphorus. Fertilization, therefore, can influence the growth rate of pines and the quality of flatwoods habitats for wildlife. Soils that are lacking in phosphorus produce poor-quality deer browse that cannot support large populations. The body weights and general condition of deer can actually be predicted through knowledge of the phosphorus levels in the soil.

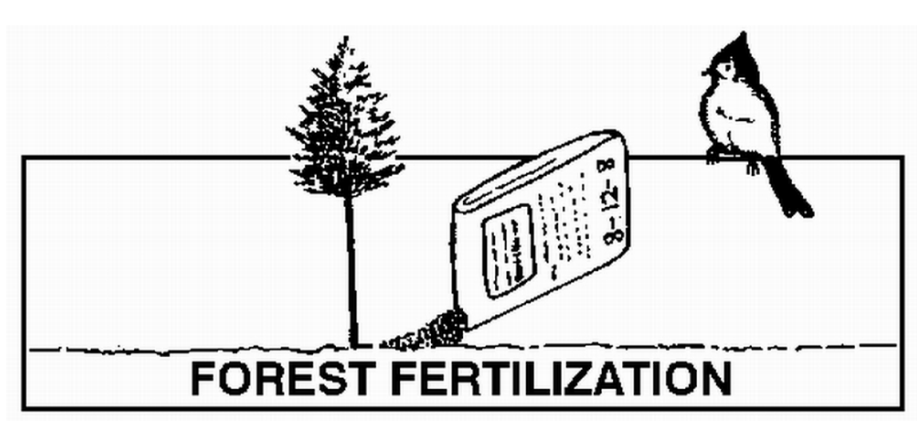

Figure 8. Fertilization can increase the rate of growth of pines.

If phosphorus is applied to the forest before crown closure or if thinning is accompanied by fertilization, then understory plants of superior quality result in enhanced forage for deer. Sometimes deer damage to pines in young plantations can become a major concern. One suggestion is to create an alternative food source by fertilizing native plants a short distance away from the affected stand. Thinning is the process of removing lesser quality trees from the forest. Thinning in pine stands reduces light competition among pines and improves both the form and growth of trees left standing. The first thinnings usually produce pulpwood that is used in the manufacture of paper products. Later 
thinnings will produce pines with 8-inch diameters at breast height $(\mathrm{DBH})$ or greater diameter chip-and-saw trees large enough to permit the production of chips and boards from the same tree. Prices for chip-and-saw trees may be much greater than those for pulpwood.

\section{Thinning}

Without thinning and burning, the lack of light penetration through the pine crowns, the root competition for water and nutrients, and the heavy accumulations of organic litter that ties up nutrients all inhibit the development of understory vegetation. Thinning is a timber stand improvement practice (TSI) that opens up the pine canopy of plantations, promoting development of the understory and midstory vegetation that is extremely important for many wildlife species. In general, thinning as early in plantation development and as often as possible is favorable both for wildlife and for forest health and productivity. Alternatively, wider spacing of seedlings can benefit wildlife by delaying canopy closure, although this may have negative effects on timber production.

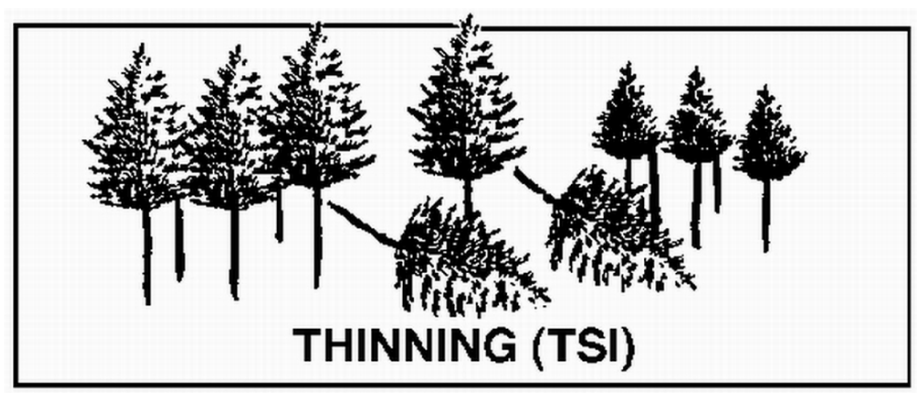

Figure 9. Thinning reduces canopy cover, improving growing conditions for groundcover and the understory.

\section{Conclusions}

Managing forested land can be a profitable and rewarding experience. It can provide a satisfying livelihood or a pleasurable pastime. But managing a multiple-use resource always involves trade-offs when making decisions. Defining priorities and making long-term plans based upon sound knowledge and experience can result in intelligent decisions.

It is as difficult to generalize about management of all wildlife as it is to generalize about all combinations of forest management. Some forest management practices are more favorable than others for some wildlife species. The key to management for favoring many wildlife species is in trying to maintain or enhance the variety of vegetation (wildlife habitats) found in an area. Generally, the greater the variety of vegetation, the greater the use of the area by wildlife. If you desire additional information on managing forests to promote wildlife, contact Extension Specialists in the Department of Wildlife Ecology and Conservation, your County Cooperative Extension, Division of Forestry, or Florida Fish and Wildlife Conservation Commission offices.

\section{Sources of Additional Information}

Demers, C. 1999. Establishing and maintaining wildlife food sources. University of Florida, IFAS Extension document SSFOR12. http://edis.ifas.ufl.edu/pdffiles/FR/ FR06200.pdf.

Long, A. J. Environmentally sound forest harvesting. University of Florida, IFAS Extension document SSFOR6. http://edis.ifas.ufl.edu/pdffiles/FR/FR04200.pdf.

Ober, H. K., S. Rosenthal, and W. Sheftall. 2009. Ten tips for encouraging the use of your pine plantations by game species. University of Florida, IFAS Extension document WEC 273. http://edis.ifas.ufl.edu/pdffiles/UW/UW31800. pdf.

Ober, H. K., S. Rosenthal, and W. Sheftall. 2009. Ten tips for increasing wildlife diversity in pine plantations. University of Florida, IFAS Extension document WEC 274. http://edis. ifas.ufl.edu/pdffiles/UW/UW31900.pdf.

Schaefer, J. Helping cavity-nesters in Florida. University of Florida, IFAS Extension document SSWIS901. http://edis. ifas.ufl.edu/pdffiles/UW/UW05800.pdf. 
Table 1. General impacts of intensive management of pine plantations on selected wildlife as determined from a thorough literature review.

\begin{tabular}{|c|c|c|c|c|c|c|c|c|c|c|c|}
\hline \multirow[t]{3}{*}{ SPECIES } & \multicolumn{6}{|c|}{ CLEARCUT STAGE } & \multicolumn{5}{|c|}{ PLANTATION STAGE } \\
\hline & \multicolumn{2}{|c|}{ Clearcut size } & \multicolumn{4}{|c|}{ Site Preparation } & \multirow[t]{2}{*}{ Fertilization } & \multicolumn{2}{|c|}{ Burn } & \multirow[t]{2}{*}{ Thin } & \multirow{2}{*}{$\begin{array}{c}\text { Hardwood } \\
\text { \&Snag } \\
\text { Removal }\end{array}$} \\
\hline & $\begin{array}{l}<100 \\
\text { Acres }\end{array}$ & $\begin{array}{l}>100 \\
\text { Acres }\end{array}$ & $\begin{array}{c}\text { Snag } \\
\text { Removal }\end{array}$ & Burn & Chop & Windrow & & $\begin{array}{c}1-2 \\
\text { year }\end{array}$ & $\begin{array}{c}3-5 \\
\text { year }\end{array}$ & & \\
\hline White-tailed Deer & + & - & & + & + & + & + & & ++ & ++ & -- \\
\hline Turkey & + & - & & & & & & + & ++ & & -- \\
\hline Gray Squirrel & - & - & & - & - & & & & & & -- \\
\hline Bobwhite & ++ & + & & ++ & + & ++ & & ++ & & ++ & \\
\hline Wild Hog & & & & & & & & & & & -- \\
\hline Mourning Dove & ++ & ++ & - & & & & & & & & \\
\hline Cottontail Rabbit & ++ & ++ & & + & + & + & & & & & \\
\hline Fox Squirrel & - & - & & & & & & & & & -- \\
\hline
\end{tabular}

